\title{
Generalized Spike-Waves, Multiple Loci, and Clinical Course in Children with EEG Features of Benign Epilepsy of Childhood with Centrotemporal Spikes
}

\author{
Ahmad Beydoun, Elizabeth A. Garofalo, and Ivo Drury \\ Departments of Neurology and Pediatrics, University of Michigan Medical School, Ann Arbor, Michigan, U.S.A.
}

Summary: In 41 patients with EEG features of benign epilepsy of childhood with centrotemporal spikes (BECCT), we noted associated generalized spike-wave discharges (GSWD) in 14.6\% and multiple independent sharp wave foci in $9.8 \%$. The presence or absence of these EEG features was not predictive of the clinical course. The high incidence of GSWD in children with BECCT suggests a possible relation in the expression of these two EEG traits. Key Words: Benign epilepsy of childhood-Electroencephalography_Child-Seizures.
Benign epilepsy of childhood with centrotemporal spikes (BECCT) is a common electroclinical syndrome of childhood, characterized clinically by easily controlled seizures affecting an otherwise normal child (Lerman and Kivity-Ephraim, 1974). Electrographically, distinct monomorphic sharp waves with blunted peaks are evident in the centrotemporal area or occasionally in other locations (Lüders et al., 1987; Drury and Beydoun, 1991). The seizures, when nocturnal, may be partial or generalized tonic-clonic. Diurnal seizures most commonly present as speech difficulties or sensorymotor symptoms affecting the face and upper extremity (Beaussart, 1972), although diverse seizure patterns have been described (Loiseau and Beaussart, 1973). The seizures abate, and the EEG becomes normal in almost all patients by adolescence (Loiseau et al., 1983). Atypical EEG features in this syndrome are the appearance of generalized spikewave discharges (GSWD) or the occurrence of more than two independent sharp wave foci. Despite extensive studies, controversy exists about the incidence of associated GSWD on EEG, with reported rates varying between 0 and $55 \%$ (Lombroso, 1967; Beaussart, 1972; Blom et al., 1972;

Received October 1991; revision accepted March 1992.

Presented in part at the 1989 meeting of the American EEG Society.

Address correspondence and reprint requests to Dr. A. Beydoun at Electrodiagnostic Laboratory, University Hospital 1B300, 1500 E. Medical Center Dr., Ann Arbor, MI 48109-0036, U.S.A.
Beaumanoir et al., 1974; Lerman and Kivity, 1975; Dalla Bernardina and Beghini, 1976; Lüders et al., 1987). The incidence of multiple independent sharp wave foci (MISWF) in this syndrome and the associated clinical course have rarely been reported (Dalla Bernardina and Beghini, 1976; Lüders et al., 1987). Consequently, we wished to determine the incidence of GSWD and MISWF in patients meeting EEG criteria of BECCT, compare the clinical course of patients with typical and atypical EEG findings, and determine whether the incidence of GSWD is more common in patients with EEG features of BECCT than in the general population.

\section{MATERIAL AND METHODS}

All EEGs recorded from children aged 2-18 years between April 1986 and April 1989 at the University of Michigan EEG laboratory were retrospectively reviewed for focal epileptiform activity. Inclusion criteria for EEG features of BECCT were rigorous. Only records that met each of the following criteria were included:

1. Normal background features (mild background slowing was accepted if attributable to medication effect)

2. Focal, monomorphic, di- or triphasic sharp waves with blunted peaks increasing in frequency during drowsiness or sleep if those states were achieved 
3. Absence of focal slowing

4. Absence of other types of focal epileptiform activity

MISWF was defined as three or more independent foci from noncontiguous areas, with at least one discharge from each hemisphere, each satisfying the morphologic and activation criteria. Recordings were made on 21-channel instruments, with electrodes placed according to the International 1020 system, and use of referential, longitudinal bipolar and transverse bipolar montages. Hyperventilation and photic stimulation were performed on all patients.

Fifty EEGs from 41 patients satisfied the EEG criteria for BECCT and were reviewed for associated GSWD or MISWF. We were careful to distinguish GSWD from physiologic patterns such as hypnogogic hypersynchrony or bilateral independent discharges appearing synchronously and mimicking a generalized discharge. In addition, several features characterizing the focal sharp waves were analyzed, including hemispheric lateralization, the number of independent foci, the presence of a horizontal dipole, the number of discharges in various states, the presence of a preceding positive potential or aftergoing slow wave, and the effect of photic stimulation and hyperventilation. The occurrence of a horizontal dipole was assessed from the referential montage to ipsilateral ear and considered present if a bianterior positivity was noted synchronously with the discharges (Gregory and Wong, 1984). The relative numbers of sharp waves in wakefulness, drowsiness, and sleep were determined by counting during 5 -min epochs.

After we reviewed their medical records, we divided the 41 children into three clinical groups according to their history and clinical course: (a) children who met the clinical criteria for BECCT (described below); (b) children with seizures who did not satisfy the clinical criteria for BECCT; and (c) children without seizures or with only a history of febrile seizures.

Patients in the first group satisfied each of the following clinical criteria for BECCT: (a) nocturnal partial or generalized tonic-clonic seizures (GTCS) and/or daytime partial or secondarily GTCS; (b) normal development and normal neurologic examination; and (c) no other seizure types. The incidence of GSWD and MISWF in each of the three clinical groups was calculated. The distribution of children in each of the three clinical groups was compared according to the presence or absence of associated GSWD or MISWF (Fisher's test). The characteristics of the sharp waves were compared according to the presence or absence of associated GSWD or MISWF (Fisher's test).

\section{RESULTS}

There were 22 boys (54\%) and 19 girls (46\%) with an average age of 8 years (range 2.5-14.5 years). The group that met the electroclinical criteria of BECCT consisted of 19 children (46\%): 11 boys and 8 girls. Their average age at the time of recording was 7.5 years (range $2.5-12$ years) and their average age at seizure onset was 6 years (range 2-10.5 years). Eight children had typical orofacial seizures with or without speech arrest, 8 had nocturnal focal motor or GTCS, 1 had right focal motor seizures that secondarily generalized, and one had right focal motor seizures with deviation of the head to the right. Twelve children underwent brain computed tomography (CT) scans, all of which were normal.

The group with seizures that did not satisfy the clinical criteria of BECCT consisted of 13 children (32\%): 8 boys and 5 girls. Their average age at the time of recording was 8.5 years (range 4.5-14.5 years), and their average age at seizure onset was 5 years (range 6 months to 11 years). Two children had mild developmental delay and otherwise typical orofacial seizures with or without speech arrest. Two had a history of absence seizures, with coexisting GTCS in 1. Two had a history of diurnal GTCS and mild developmental delay. Three children had partial complex seizures that secondarily generalized in 2 . Of the other 4 children, 1 had two seizures during the course of a viral encephalitis at age 7 years and was neurologically normal at the time of the EEG 2 months later, 1 had a history of head trauma and left focal motor seizures, 1 had refractory right focal motor seizures that started at age 6 months due to an arteriovenous malformation, and 1 was an 11-year-old girl with mild developmental delay and a history of possible infantile spasms between the ages of 6 and 12 months with no seizures since. Seven underwent brain CT scans; five were normal, one showed a right frontotemporal contusion, and the other showed a calcified arteriovenous malformation in the left parietal white matter.

The third group consisted of 9 children (22\%): 3 boys and 6 girls. Their average age at the time of recording was 7.5 years (range 4.5-11 years). Four children had behavioral disorders but no history of seizures, and 4 had a history of febrile seizures.

Six children $(14.6 \%, 3$ boys and 3 girls) had GSWD noted independent of hyperventilation or photic stimulation (Fig. 1). Four had atypical spikewaves (generalized 4- to $6-\mathrm{Hz}$ spikes or polyspikewaves), and 1 each had $3-\mathrm{Hz}$ spike-wave and slow spike-wave discharges. Two of these children met 


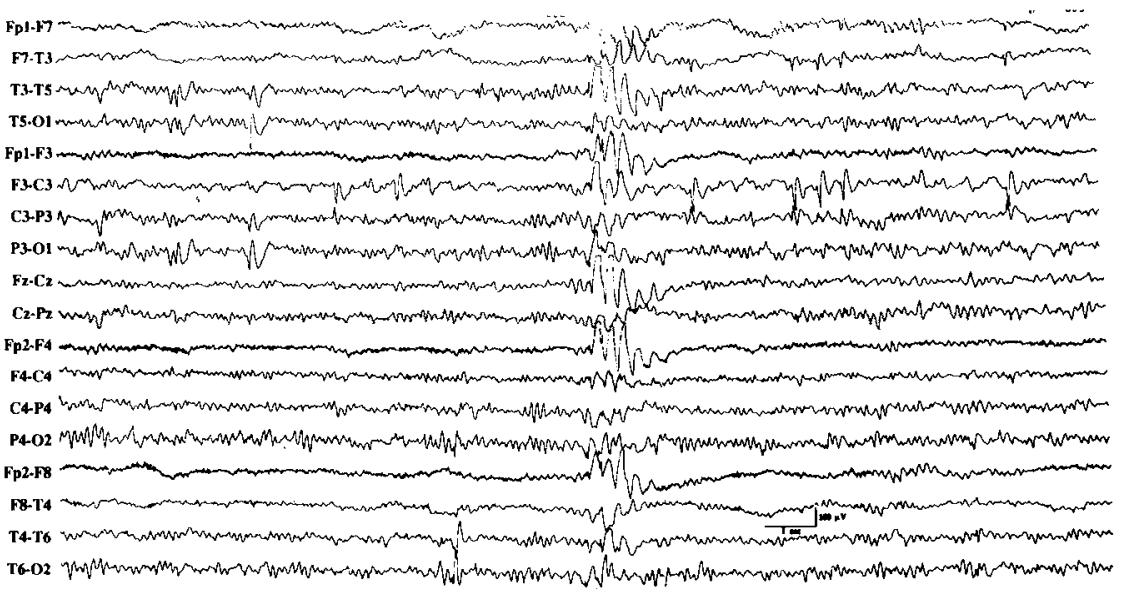

FIG. 1. EEG of 8-year-old girl during drowsiness. Single generalized spikewave discharge and multiple independent sharp wave foci are evident at C3$T 3,01$, and $T 6$. criteria for the electroclinical syndrome (1 had a single orofacial partial motor seizure, and the other had infrequent partial motor seizures affecting the face and hand), 2 were referred because of febrile seizures, and 2 were developmentally delayed, one with diurnal GTCS and the other with speech arrest and left focal motor seizures (Table 1).

Four children $(9.8 \%, 1$ boy and 3 girls) had MISWF (Figs. 1 and 2). Two had the electroclinical syndrome with typical seizures, 1 was referred because of viral encephalitis and seizures, and the other had GTCS and developmental delay (Table 1). The distribution of clinical diagnoses was not statistically different whether the EEG pattern was typical or also showed GSWD or MISWF (Table 1).

The sharp waves were restricted to the right hemisphere in $32 \%$ of the records, to the left hemisphere in $30 \%$, and were bilateral in $38 \%$. There was a single focus in $62 \%$, two foci in $30 \%$, and three foci in $8 \%$ (Table 2). Table 3 summarizes the principal characteristics of the sharp waves in each of the three categories. A horizontal dipole was identified in $52 \%$ of the records. There was a preceding positivity in $28 \%$ and an aftergoing slow wave in $74 \%$ of the records. Background EEG activity was normal in $88 \%$ and mildly slow in $12 \%$. Photic stimulation and hyperventilation did not activate the focal sharp waves in any child. The average number of discharges for all records during a 5-min epoch was 43 during wakefulness, 85 during drowsiness, and 121 in sleep. These various features of the focal sharp waves were not statistically different among the EEGs with typical features, those showing MISWF, or EEGs with associated GSWD.

\section{DISCUSSION}

The incidence of GSWD in children with EEG features of BECCT is of interest because of the very nature of this syndrome. Although the epileptiform discharges and the typical seizures are focal in this syndrome, BECCT shares many characteristics with the idiopathic generalized epilepsies. Onset is in childhood between the ages of 3 and 13 years, family histories suggest an autosomal dominant inheritance with variable penetrance, development and neurologic findings are normal, and seizures are easily controlled and remit by adolescence in almost all cases.

In our series, $14.6 \%$ of children with EEG fea-

TABLE 1. Incidence of GSWD and MISWF and associated clinical course of BECCT

\begin{tabular}{|c|c|c|c|c|c|}
\hline Parameter & $\begin{array}{l}\text { Typical EEG } \\
\text { features }\end{array}$ & $\begin{array}{l}\text { Typical and } \\
\text { GSWD }\end{array}$ & $\begin{array}{l}\text { Typical and } \\
\text { MISWF }\end{array}$ & Total & $\%$ \\
\hline $\begin{array}{l}\text { Electroclinical syndrome } \\
\text { of BECCT }\end{array}$ & 16 & 2 & 2 & $19^{a}$ & 46.3 \\
\hline $\begin{array}{l}\text { Seizures but not } \\
\text { electroclinical syndrome } \\
\text { of BECCT }\end{array}$ & 9 & 2 & 2 & 13 & 31.7 \\
\hline $\begin{array}{l}\text { No seizures or only } \\
\text { febrile seizures }\end{array}$ & 7 & 2 & 0 & 9 & 22 \\
\hline Total & 32 & 6 & 4 & $41^{a}$ & 100 \\
\hline Percentage & 78 & 14.6 & 9.8 & & \\
\hline
\end{tabular}

GSWD, generalized spike-wave discharges-MISWF, multiple independent sharp wave foci; BECCT, benign epilepsy of childhood with centrotemporal spikes.

${ }^{a}$ One patient had both GSWD and MISWF. 


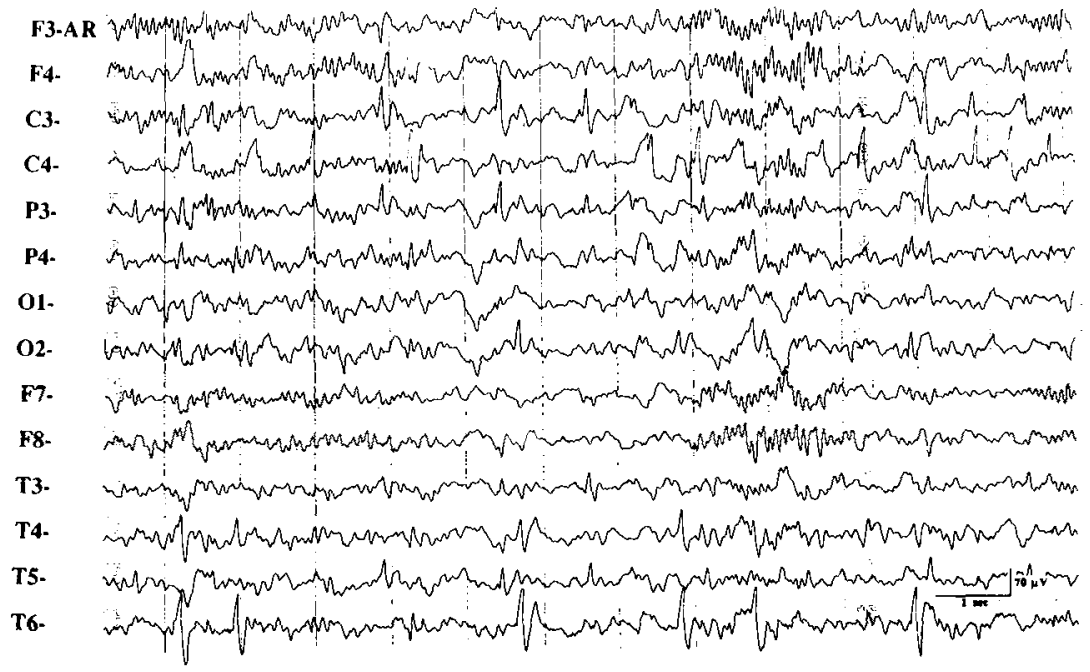

FIG. 2. Sleep EEG of 13-year-old boy. Multiple independent sharp wave foci are maximal at $\mathrm{C} 3, \mathrm{C} 4$, and $\mathrm{T} 6$. tures of BECCT had associated GSWD. Previous series (Table 4) reported a GSWD incidence ranging from 0 to $55 \%$, this wide range reflecting different criteria for case selection and variable interpretation of what constitutes GSWD. Three previous series used inclusion criteria comparable to ours based on EEG findings but studied only patients who also fulfilled the clinical criteria of BECCT (Lombroso, 1967; Beaussart, 1972; Lerman and Kivity, 1975). The incidence of associated GSWD in these series was $12.1,6.8$, and $7.0 \%$, respectively. We noted a similar incidence of GSWD in the children who fulfilled the electroclinical syndrome, since 2 of 19 had associated GSWD (10.5\%). In the two series with higher GSWD incidence rates of 53.8 and 25\% (Beaumanoir et al., 1974; Dalla Bernardina and Beghini, 1976) as well as the series of Lüders et al. (1987), the inclusion criteria either were not well defined or were not specified.

In addition to strict electrographic and clinical inclusion criteria to assure a reliable diagnosis of the electroclinical syndrome of BECCT, the coexistence of GSWD must be distinguished from four other EEG features common in children with seizures.

1. The interictal EEG in idiopathic generalized epilepsy frequently shows fragments of spike-

TABLE 2. Number of foci according to EEG features in $B E C C T$

\begin{tabular}{ccccc}
\hline Foci & $\begin{array}{c}\text { Typical EEG } \\
\text { features }\end{array}$ & $\begin{array}{c}\text { Typical and } \\
\text { GSWD }\end{array}$ & $\begin{array}{c}\text { Typical and } \\
\text { MISWF }\end{array}$ & Total \\
\cline { 2 - 5 } 1 & 26 & 5 & - & 31 \\
2 & 14 & 1 & - & 15 \\
3 & 0 & 1 & 4 & $4^{*}$ \\
\hline
\end{tabular}

Abbreviations as in Table 1.

a One record had both GSWD and MISWF. wave discharges in addition to GSWD. These focal discharges are usually located in the frontal areas but can occur elsewhere. They may shift between hemispheres, but more important, they are low-amplitude spikes that differ morphologically from the typical sharp waves of BECCT.

2. EEGs typical of BECCT will occasionally display bilateral independent discharges appearing synchronously and mimicking a GSWD (Fig. 3). This pattern, most common during drowsiness or sleep, can be differentiated from GSWD by the occasional presence of a horizontal dipole, some interhemispheric asynchrony (Blume, 1982; Lüders et al., 1987), or the morphology of the discharges, because even when enlarged in field and amplitude, the sharp waves retain their typical morphology.

3. The EEG in a symptomatic generalized epilepsy may show focal or multifocal spikes in addition to the generalized discharges. The focal or diffuse slowing as well as the morphology of the focal spikes differentiate this pattern from that of BECCT.

TABLE 3. Distribution of sharp wave characteristics according to EEG features in BECCT

\begin{tabular}{lcccc}
\hline \multicolumn{1}{c}{ Parameter } & $\begin{array}{c}\text { Typical } \\
\text { EEG } \\
\text { features }\end{array}$ & $\begin{array}{c}\text { Typical } \\
\text { and } \\
\text { GSWD }\end{array}$ & $\begin{array}{c}\text { Typical } \\
\text { and } \\
\text { MISWF }\end{array}$ & Total \\
\hline Number of EEGs & 40 & 7 & 4 & $50^{a}$ \\
Horizontal dipole & 21 & 4 & 2 & $26^{a}$ \\
Preceding positivity & 12 & 1 & 1 & 14 \\
Aftergoing slow wave & 30 & 5 & 3 & $37^{a}$ \\
Mild slowing & 5 & 1 & 0 & 6 \\
\hline
\end{tabular}

Abbreviations as in Table 1.

a One record had both GSWD and MISWF. 
TABLE 4. Reported incidence of GSWD in BECCT

\begin{tabular}{lccc}
\hline \multicolumn{1}{c}{ Series } & $\begin{array}{c}\text { No. of } \\
\text { patients }\end{array}$ & GSWD & $\begin{array}{c}\text { Percentage } \\
\text { of GSWD }\end{array}$ \\
\hline Lombroso, 1967 & 58 & 7 & 12.1 \\
Blom et al., 1972 & 40 & 3 & 7.5 \\
Beaussart, 1972 & 221 & 15 & 6.8 \\
Beaumanoir et al., 1974 & 26 & 14 & 53.8 \\
$\begin{array}{l}\text { Lerman and } \\
\quad \text { Kivity, 1975 }\end{array}$ & 100 & 7 & 7.0 \\
$\begin{array}{l}\text { Dalla Bernardina } \\
\quad \text { and Beghini, 1975 }\end{array}$ & 20 & 5 & 25.0 \\
$\begin{array}{l}\text { Lüders et al., 1987 } \\
\text { Beydoun et al., }\end{array}$ & $?$ & 0 & 0.0 \\
$\quad$ this series & 41 & 6 & 14.6 \\
Total & & & \\
\hline
\end{tabular}

${ }^{a}$ Excluding the series of Lüders et al.

4. Physiologic patterns such as hypnogogic hypersynchrony or rhythmic slowing provoked by hyperventilation must be distinguished from GSWD.

Because the EEG patterns of BECCT and GSWD are both common, it has been suggested that their coexistence may be due to chance alone (Lüders et al., 1987). Cavazzuti et al. (1980) studied the EEGs of 3,726 normal children and reported that 37 had generalized epileptiform discharges, an incidence of $1 \%$. Although the latter population and ours are not identical, we noted a 14-fold increase in the incidence of GSWD in children with EEG patterns of BECCT. Because both patterns are genetically transmitted with an age-dependent penetrance (Metrakos and Metrakos, 1961; Heijbel et al., 1975), our data suggest a possible relation in the expression of these two EEG traits.

Most children with EEG manifestations of BECCT will not have clinical epilepsy (Fois et al., 1968; Lerman and Kivity-Ephraim, 1981). That 22\% of children in this series had no seizures or only febrile seizures is not surprising. Thirty-two percent of our patients had seizures but did not fulfill our strict clinical criteria of BECCT. Although most investigators have evaluated primarily patients with seizures and no neurologic deficit, children with developmental delay or structural lesions can have typical seizures and a clinical course perfectly compatible with this electroclinical syndrome (Blom et al., 1972; Santanelli et al., 1989). In such cases, two conditions, i.e., BECCT and the neurologic deficit, coexist without mutual interaction (Lüders et al., 1987). In our series, 4 of the 9 children in this category would have fulfilled the clinical criteria if not for mild developmental delay and should for clinical purposes be considered to have the electroclinical syndrome. The other 5 children (12\%) had seizure types (partial complex or absence) not seen in BECCT (Lombroso, 1967; Blom et al., 1972) or sei- zures clearly related to a structural lesion or CNS infection. Thus, a child with seizures and EEG findings of BECCT cannot be assumed to have this syndrome unless the seizure types, response to treatment, and clinical course are consistent with this diagnosis.

The clinical course of children with the EEG pattern of BECCT and associated GSWD was reported in only one previous series (Dalla Bernardina and Beghini, 1976). They noted GSWD in $40 \%$ of patients with rolandic spikes and epilepsy and in 10\% of children with rolandic spikes without epilepsy, suggesting that a child with associated GSWD has a higher risk of seizures. Our data do not support their conclusion since 2 of 9 patients with no history of seizures or only febrile seizures and 2 of 19 children with the electroclinical diagnosis of BECCT had GSWD.

The incidence of MISWF in BECCT was reported in two series: $55 \%$ by Dalla Bernardina and Beghini (1976) and 37.5\% by Lüders et al. (1987). The high incidence in the former study probably reflects their less rigorous definition of multifocal spikes as two or more bilateral independent foci. We noted MISWF in $9.5 \%$ of children with EEG features of BECCT and in $10.5 \%$ of children with the electroclinical syndrome. Dalla Bernardina and Beghini (1976) suggested that a child is less likely to have seizures if the EEG shows multifocal discharges since they noted this pattern in $20 \%$ of children with epilepsy and in $90 \%$ without epilepsy. Our data do not support their conclusion because we noted no statistical difference in the clinical course among children with one, two, or more foci.

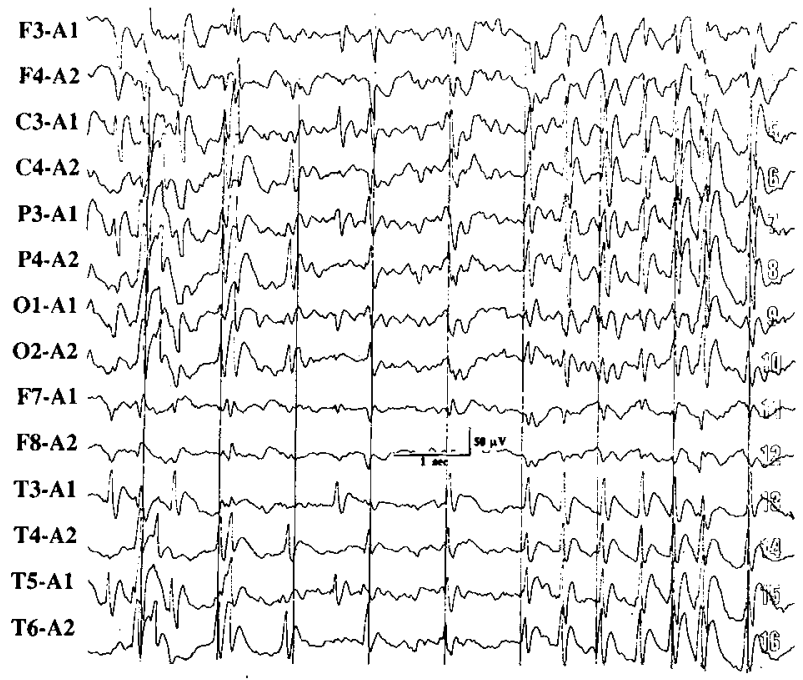

FIG. 3. EEG of 6 year-old boy during drowsiness; 3 -s epoch of bilaterally synchronous sharp-and-slow waves maintaining morphology identical to preceding bilateral independent activity. 
Acknowledgment: We thank Dr. Chris Vanderzant for manuscript review and Sally Mouilleseaux for assistance in manuscript preparation.

\section{REFERENCES}

Beaumanoir A, Ballis T, Varfis G, Ansari K. Benign epilepsy of childhood with rolandic spikes. Epilepsia 1974;15:301-15.

Beaussart M. Benign epilepsy of children with rolandic (centrotemporal) paroxysmal foci. A clinical entity. Study of 221 cases. Epilepsia 1972;13:795-811.

Blom S, Heijbel J, Bergfors PG. Benign epilepsy of children with centrotemporal EEG foci. Prevalence and follow-up study of 40 patients. Epilepsia 1972;13:609-19.

Blume WT. Atlas of pediatric electroencephalography. New York: Raven Press, 1982:144-5.

Cavazzuti GB, Cappella L, Nalin A. Longitudinal study of epileptiform EEG patterns in normal children. Epilepsia 1980; 21:43-55.

Dalla Bernardina B, Beghini G. Rolandic spikes in children with and without epilepsy (20 subjects polygraphically studied during sleep). Epilepsia 1976;17:161-7.

Drury I, Beydoun A. Benign epilepsy of childhood with monomorphic sharp waves in centrotemporal and other locations. Epilepsia 1991;32:662-7.

Fois A, Borgheresi S, Luti E. Clinical correlates of focal epileptic discharges in children without seizures: a study of 110 cases. Helv Paediatr Acta 1968;3:257-65.

Gregory DL, Wong PK. Topographical analysis of the centrotemporal discharges in benign rolandic epilepsy of childhood. Epilepsia 1984;25:705-11.

Heijbel J, Blom S, Rasmuson M. Benign epilepsy of childhood with centrotemporal EEG foci: a genetic study. Epilepsia 1975;16:285-93.

Lerman P, Kivity S. Benign focal epilepsy of childhood. A follow-up study of 100 recovered patients. Arch Neurol 1975; 32:261-4.

Lerman P, Kivity-Ephraim S. Carbamazepine sole anticonvulsant for focal epilepsy of childhood. Epilepsia 1974;15:229 34.

Lerman P, Kivity-Ephraim S. Focal epileptic EEG discharges in children not suffering from clinical epilepsy: etiology, clinical significance and management. Epilepsia 1981;22:551-8.

Loiseau P, Beaussart M. The seizures of benign childhood epi- lepsy with rolandic paroxysmal discharges. Epilepsia 1973; $14: 381-9$

Loiseau P, Pestre M, Dartigues JF, Commenges D, BarbegerGateau C, Cohadon S. Long term prognosis in two forms of childhood epilepsy: typical absence seizures and epilepsy with rolandic (centrotemporal) EEG foci. Ann Neurol 1983; 13:642-8.

Lombroso CT. Sylvian seizures and midtemporal spike foci in children. Arch Neurol 1967;17:52-9.

Lüders H, Lesser RP, Dinner DS, Morris HH. Benign focal epilepsy of childhood. In: Lüders H, ed. Epilepsyelectroclinical syndromes. Berlin: Springer-Verlag, 1987: 303-46.

Metrakos K, Metrakos JD. Genetics of convulsive disorders. Genetic and electroencephalographic studies in centrencephalic epilepsy. Neurology 1961;11:474-83.

Santanelli P, Bureau M, Magaudda A, Gobbi G, Roger J. Benign partial epilepsy with centrotemporal (or rolandic) spikes and brain lesion. Epilepsia 1989;30:182-8.

\section{RÉSUMÉ}

Chez 41 patients présentant les caractéristiques EEG de l'épilepsie bénigne de l'enfance avec pointes centro-temporales (BECT), les auteurs ont trouvé des décharges de pointes-ondes généralisées dans $14.6 \%$ des cas et des foyers multiples indépendants dans $9.8 \%$ des cas. La présence ou l'absence de ces caractéristiques EEG ne permettait pas de prédire l'évolution clinique. La forte incidence de pointes-ondes généralisées chez des enfants avec une BECT suggère une relation possible dans l'expression de ces deux traits EEG.

(P. Genton, Marseille)

\section{ZUSAMMENFASSUNG}

Bei 41 Patieten mit dem EEG-Merkmal einer benignenkindlichen Epilepsie mit zentrotemporalen spikes (BECCT) fanden wir generalisierte SWK in $14.6 \%$ und unabhängige sharpwave Foci in $9.8 \%$. Das Vorhandensein oder Fehlen dieser encephalographischen Merkmale hatte keinen Einfluß auf den klinischen Verlauf. Die hohe Inzidenz von SWK bei Kidnern mit BECCT läßt eine mögliche Verwandtschaft zwischen den zwei EEG-Merkmalen vermuten.

(C. G. Lipinski, Heidelberg/Neckargemünd) 